\title{
The Influence of Stress on Body Mass Index among Female University Students
}

\author{
Nada Fahad M Alsultan', Malik Dham Alanazi ${ }^{1}$, Ayat Abdulnasser Boholigah ${ }^{2}$, Daham Obaid \\ Alshammari $^{1}$, Kawthar Ali Alnahwi ${ }^{2}$, Zahrah Ali Alsayafi ${ }^{1}$, Yahya Mohammed Alzahrani ${ }^{1}$, \\ Lama Zaki Nasserullah ${ }^{2}$, Lina Zaki Nasserullah ${ }^{2}$
}

\section{1- Student, King Faisal University, 2-Student, Arabian Gulf University}

\begin{abstract}
:
Background: The interrelatedness between obesity and psychological problems seems to be twofold, in that clinically meaningful psychological distress might foster weight gain and obesity may lead to psychosocial problems. Stress may contribute to changes in dietary behaviors that lead to weight change, with various effects related to sex baseline body mass index, or cortisol reactivity in response to stress. Objective: To describe the relationship between stress, weight-related health behaviors (e.g., eating behaviors, physical activity, sedentary behavior, sleep, cigarette smoking and binge drinking), and weight status using cross-sectional data from community college students. Methods: This was a community-based cross-sectional study. Data were collected from representative sample of undergraduate female students in Kingdom of Saudi Arabia. A total of 208 undergraduate female students were included in this study. The study period was from October 2017 to December 2017. Data were collected by means of personal interview with the participants using a predesigned questionnaire which was distributed among students and filled by personal interviewing after a brief introduction or explanation of the idea of the research to the participants . Results: There was a high significant correlation between stress and $\mathrm{BW}(\mathrm{P}=0.004)$. We found no relation between $\mathrm{BW}$ and academic year, fast food consumption, main meal content, muscular exercise and cause of stress. There was a high significant correlation between $\mathrm{BW}$ and number of meals per day $(\mathrm{P}=0.000)$, stress level $(\mathrm{P}=0.000)$ and dealing with stress $(\mathrm{P}=0.017)$. Conclusion and Recommendations: Factors which were significantly associated with BMI and stress should be further studied to include number of meals per day, stress level and dealing with stress). Interventions among university students should relate actual measured BMI to stress perception of the students in order to target students at risk. Universities should offer individual counselling for at risk students in order to prevent eating disorders, and should offer psychological and stress related counselling, but should also counteract unrealistic body image concerns of students by broad health communication campaigns.
\end{abstract}

Keywords: University students, BMI, Stress, Influence, Dietary behaviors, Muscular exercise

\section{Introduction:}

Obesity is one of the major non-communicable diseases in recent decades leading to huge morbidity, mortality \& economic losses. Obesity is perhaps the most prevalent form of malnutrition. Overweight and obesity are the fifth leading risk of global deaths [1]. Prevalence of obesity and an overweight status within the college student populace has become a rapidly increasing occurrence. The population with the most dramatic rise in rates of overweight and obesity appear to be within the 18 to 29 age range, with those participating in a college education representing the most prominent increase ${ }^{[2]}$. Weight disorders are responsible for a number of health problems some of which include; for underweight: increased risk of anemia ${ }^{[3]}$, osteoporosis ${ }^{[4]}$, 'in women it can lead to amenorrhea ${ }^{[5]}$, and for overweight or obesity: type II diabetes, coronary heart disease, high blood pressure (hypertension), High cholesterol level (dyslipidemia) ${ }^{[6]}$. Young adults enrolled in university or college are subjected to high levels of stress from a number of factors that can lead to maladaptive coping mechanisms such as convenience eating in the form of eating out at fast food establishments and ordering food for delivery. This form of convenience eating offers calorie dense, high in saturated fat, and processed options that promote an increase in weight status along with other deleterious health outcomes. It is usually observed that college students undergo tremendous stress during various stages of the education. It characterized many psychological changes in students ${ }^{[7]}$. High levels of stress 
may have a negative effect on physical and mental health of the medical students. This can lead to mental distress and has a negative effect on attentive functioning and learning ${ }^{[8]}$. Psychosocial stress has also been implicated as a risk factor for high blood pressure, cardiovascular disease, and cancer ${ }^{[9]}$.

The interrelatedness between obesity and psychological problems seems to be twofold, in that clinically meaningful psychological distress might foster weight gain and obesity may lead to psychosocial problems ${ }^{[10]}$. Stress may contribute to changes in dietary behaviors that lead to weight change, with various effects related to sex ${ }^{[11]}$ baseline body mass index ${ }^{[12]}$, or cortisol reactivity in response to stress ${ }^{[13]}$. These factors may cause some people to gain more weight under stressful circumstances, while others may gain less weight or even lose weight when stressed. A longitudinal cohort study conducted in populations outside the United States has produced mixed results. Kivimaki et al. ${ }^{[12]}$ used the Whitehall study, a prospective cohort of British civil servants, to analyze the prospective association between stress and weight change over 5 years. They found that stress was associated with weight gain among men who were overweight or obese at baseline, but a similar association was not observed among women. There is growing research on the correlation and possible physiological and behavioral mechanisms between stress and obesity risk. High stress has been linked to weight gain and adiposity and appears to inhibit successful weight loss [13]. Hormones that activate stress response also play a role in appetite regulation and reward-seeking, which may affect health behaviors like eating behavior, cigarette smoking, and alcohol use ${ }^{[14]}$. Stress has also been shown to influence metabolic function, including insulin resistance ${ }^{[15]}$.

Dahlin et al. ${ }^{[16]}$ showed that the prevalence of depressive symptoms among Swedish students was $12.9 \%$ and a total of $2.7 \%$ of students had made suicidal attempts ${ }^{[16]}$.

Another study conducted on medical Students of Jorhat Medical College and Hospital, Jorhat [17] reported that; the prevalence of highly stressed students in our study is $36.2 \%$ and that of very highly stressed students is $39.1 \%$.For simplicity, if we combine highly and very highly stressed level as stressed and average and low level as non-stressed students, then overall prevalence of stress will be $75.3 \%$ in the study. In this study, we have not found any significant difference in prevalence of stress among male and female. The prevalence rate of obese (03.6\%) and overweight (15.9\%) is not very high. But found a strong correlation between psychological stress and body weight. In addition, it was found that higher stress was associated with higher prevalence of overweight/obesity, though the relationship was no longer statistically significant after controlling for a wide range of weight-related health risk behaviors. Stress levels were significantly associated with meal skipping and being a current smoker ${ }^{[18]}$.

A study carried at University of Rhode Island indicated that stress was positively correlated with BMI and waist circumference in females, but not in males. Females reported higher levels of stress and scored higher on all four subscales of the Weight Related Eating Questionnaire (WREQ) compared to males. There were significant stress and gender interaction effects for routine restraint and compensatory restraint scores ${ }^{[15]}$.

The aim of this manuscript was to describe the relationship between stress, weight-related health behaviors (e.g., eating behaviors, physical activity, sedentary behavior, sleep, cigarette smoking and binge drinking), and weight status using cross-sectional data from community college students.

\section{Participants and Methods: \\ Research design:}

This is a community-based cross-sectional study .

\section{Research environment:}

Data were collected from representative sample of undergraduate female students in Kingdom of Saudi Arabia

\section{Research instruments:}

A pre-designed questionnaire consisted of information regarding age, academic year, dietary habits, number of meals per-day, physical exercise (presents /absent), degree of exposure to stress (high/ medium/ low), the main cause of stress (family/ exams/ educational requirements/ social life) and how they deal with stress (by sleeping, drinking coffee or eating). The questionnaire consisted of 13 questions designed to match the objective of the study.

Another questions asked participants what the main content of their meal is (protein/ fats/ carbohydrate). 
The food delivery questions considered the dependent variables of the study. The questions were added to assess the eating out and food delivery frequency engaged in by participants.

The body weight $(\mathrm{kg})$ and height $(\mathrm{m})$ of each participant was measured.

The BMI was calculated (body weight in $\mathrm{kg} / \mathrm{height}$ in $\mathrm{m}^{2}$ ), and classified BMI below $18.5 \mathrm{~kg} / \mathrm{m}^{2}$ was classified as underweight, 2530 as overweight, and above 30 as obese.

\section{Respondents of the study:}

A total of 208 undergraduate female students were included in this study. The study period was from October 2017 to December 2017. Participants filled the self-reported predesigned questionnaire after a brief introduction to explain the aim of the study to them.

The sample size was calculated using the sample size equation: $n=z^{2} p(1-p) / e^{2}$, considering target population less than 1000, and study power $95 \%$, and the prevalence of obesity $50 \%$. The minimum required sample was 200 students. Systematic random sampling technique was followed by interviewing every 2 nd student.

Data were collected by means of personal interview with the participants using a predesigned questionnaires which were distributed among students filled by personal interviewing after a brief introduction or explanation of the idea of the research to students. Sampled students filled out the selfreported predesigned questionnaires to collect demographic and socioeconomic data.

\section{Ethical considerations:}

Approval to carry the study was taken from the health affaire administrator of Arar city. Participants were informed that participation is completely voluntary. And written consent was obtained from each participant before being subjective with them. No names were recorded on the questionnaires. All questionnaires kept safe.

\section{Statistical treatment:}

Descriptive statistics and testing of hypothesis were used for the analysis. The data were analyzed using SPSS V.16.0 (SPSS Inc; Chicago, IL, USA). The Chi-square test was used to examine the association between different variables. $\mathrm{P}<0.05$ was considered as statistically significant.

\section{Results:}

The total number of the study participants was 104 female students. About $36.5 \%$ of participants have 3 meals per day, $34.6 \%$ have two meals, $6.7 \%$ have five or more and only $8 \%$ have one meal per day. $76 \%$ of the participants responded yes to fast food consumption. Only $2 \%$ of students reported protein as main meal content, $51.9 \%$ carbohydrate and $22.1 \%$ fat. Only $46.2 \%$ perform muscular exercise. Regarding stress level; $44.2 \%$ describes stress as medium, $25 \%$ low, $23.1 \%$ high and only $7.7 \%$ very high. $47.1 \%$ of students reported exams as the main cause of stress, $21.2 \%$ social life, $17.3 \%$ family and $14.4 \%$ for educational requirements. $18.3 \%$ of respondents deal with stress by eating, $34.6 \%$ by sleeping, $24 \%$ drink coffee and $5.8 \%$ by smoking. $73.1 \%$ of respondents found relation between $\mathrm{BW}$ and stress. About half students had normal BMI, $24 \%$ were overweight, $15.4 \%$ obese and $9.6 \%$ underweight.

There was high significant correlation between stress and $\mathrm{BW}(\mathrm{P}=0.004)$. We found no relation between BW and academic year, fast food consumption, main meal content, muscular exercise and cause of stress. There was high significant correlation between BW and number of meals per day $(\mathrm{P}=0.000)$, stress level $(\mathrm{P}=0.000)$ and dealing with stress $(\mathrm{P}=0.017)$

\section{Figure (1): BMI distribution among the studied students}

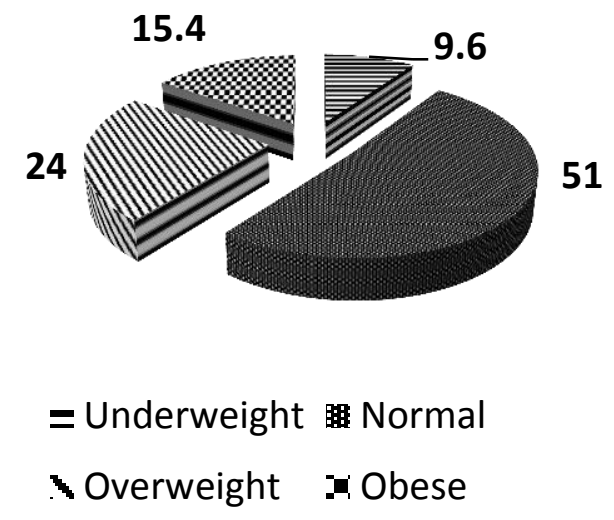


Table (1): Eating habits and stress related variables and BMI group in the studied female students

\begin{tabular}{|c|c|c|}
\hline \multicolumn{3}{|c|}{ Number of Meals per day } \\
\hline One & 5 & 4.8 \\
\hline Two & 36 & 34.6 \\
\hline Three & 38 & 36.5 \\
\hline Four & 18 & 17.3 \\
\hline Five or more & 7 & 6.7 \\
\hline \multicolumn{3}{|c|}{ Fast food consumption } \\
\hline No & 25 & 24.0 \\
\hline Yes & 79 & 76.0 \\
\hline \multicolumn{3}{|c|}{ Main meals content } \\
\hline Carbohydrate & 54 & 51.9 \\
\hline Fat & 23 & 22.1 \\
\hline Protein & 27 & 26.0 \\
\hline \multicolumn{3}{|c|}{ Performing muscular exercise } \\
\hline No & 56 & 53.8 \\
\hline Yes & 48 & 46.2 \\
\hline \multicolumn{3}{|l|}{ Stress level } \\
\hline High & 24 & 23.1 \\
\hline Low & 26 & 25.0 \\
\hline Medium & 46 & 44.2 \\
\hline very high & 8 & 7.7 \\
\hline \multicolumn{3}{|c|}{ Cause of stress } \\
\hline $\begin{array}{l}\text { Educational } \\
\text { requirements }\end{array}$ & 15 & 14.4 \\
\hline Exams & 49 & 47.1 \\
\hline Family & 18 & 17.3 \\
\hline Social life & 22 & 21.2 \\
\hline \multicolumn{3}{|c|}{ Dealing with stress } \\
\hline Sleep & 36 & 34.6 \\
\hline drink coffee & 25 & 24.0 \\
\hline Eat & 19 & 18.3 \\
\hline Smoke & 6 & 5.8 \\
\hline Other & 18 & 17.3 \\
\hline \multicolumn{3}{|c|}{ Relation between BW and stress } \\
\hline No & 28 & 26.9 \\
\hline Yes & 76 & 73.1 \\
\hline \multicolumn{3}{|l|}{ BMI group } \\
\hline Underweight & 10 & 9.6 \\
\hline Normal & 53 & 51.0 \\
\hline Overweight & 25 & 24.0 \\
\hline Obese & 16 & 15.4 \\
\hline
\end{tabular}

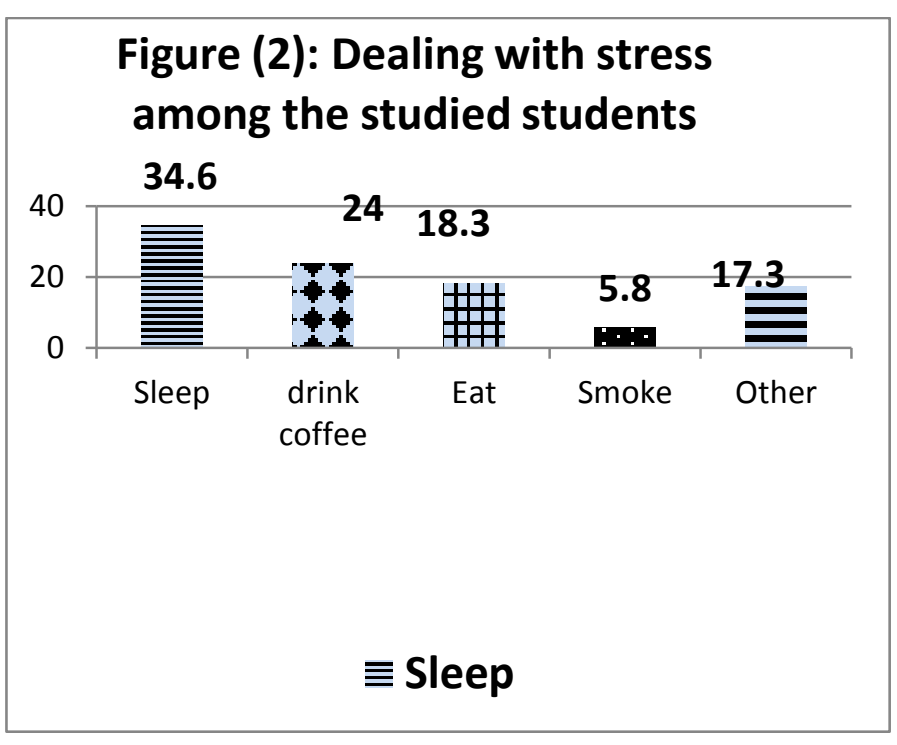

\section{Figure (3): Levels of stress among the studied students}

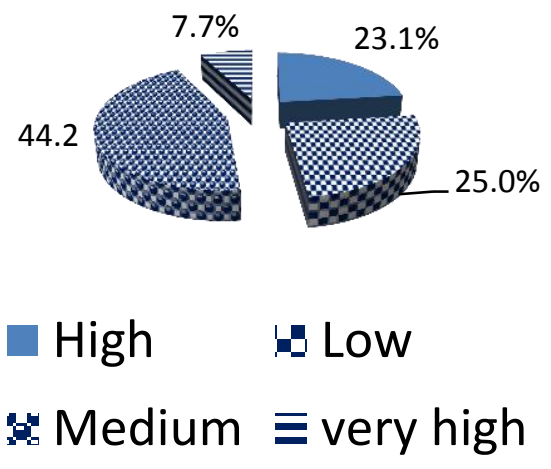

Figure (4): causes of stress in the studied students

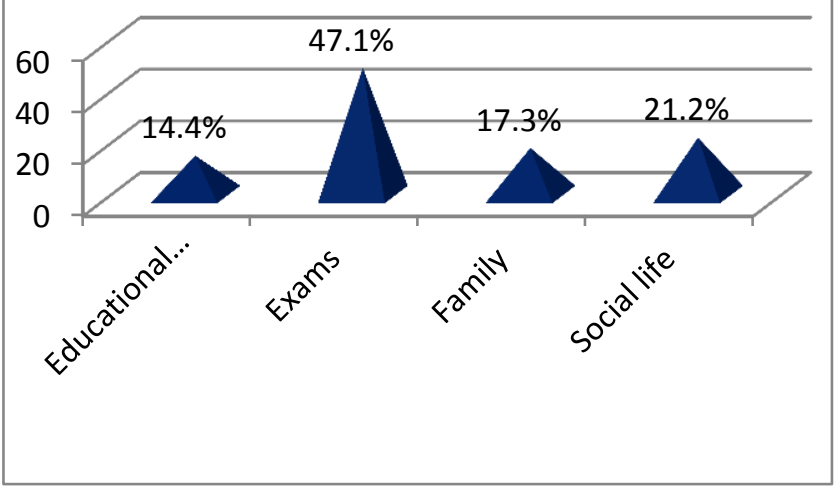


Nada Alsultan et al.

Table (2): The relationship between BMI group, academic year, eating habits and stress related variables in the studied female students

\begin{tabular}{|c|c|c|c|c|c|c|}
\hline \multirow{2}{*}{$\begin{array}{c}\text { Variable } \\
\text { Academic year }\end{array}$} & \multicolumn{4}{|c|}{ BMI group } & \multirow{2}{*}{ Total $(n=104)$} & \multirow{2}{*}{$P$ value } \\
\hline & Underweight $(\mathrm{n}=10)$ & Normal $(n=53)$ & Overweight $(n=25)$ & Obese $(n=16)$ & & \\
\hline \multirow{2}{*}{ Bridging } & 0 & 14 & 8 & 6 & 28 & 0.177 \\
\hline & $.0 \%$ & $26.4 \%$ & $32.0 \%$ & $37.5 \%$ & $26.9 \%$ & \\
\hline \multirow{2}{*}{ Regular } & 10 & 39 & 17 & 10 & 76 & \\
\hline & $100.0 \%$ & $73.6 \%$ & $68.0 \%$ & $62.5 \%$ & $73.1 \%$ & \\
\hline \multicolumn{7}{|c|}{ Number of meals daily } \\
\hline \multirow{2}{*}{ Three } & 1 & 24 & 11 & 2 & 38 & 0.000 \\
\hline & $10.0 \%$ & $45.3 \%$ & $44.0 \%$ & $12.5 \%$ & $36.5 \%$ & \\
\hline \multirow{2}{*}{ Two } & 8 & 21 & 5 & 2 & 36 & \\
\hline & $80.0 \%$ & $39.6 \%$ & $20.0 \%$ & $12.5 \%$ & $34.6 \%$ & \\
\hline \multirow{2}{*}{ Four } & 0 & 6 & 6 & 6 & 18 & \\
\hline & $.0 \%$ & $11.3 \%$ & $24.0 \%$ & $37.5 \%$ & $17.3 \%$ & \\
\hline \multirow{2}{*}{ Five or more } & 0 & 0 & 2 & 5 & 7 & \\
\hline & $.0 \%$ & $.0 \%$ & $8.0 \%$ & $31.2 \%$ & $6.7 \%$ & \\
\hline \multirow{2}{*}{ One } & 1 & 2 & 1 & 1 & 5 & \\
\hline & $10.0 \%$ & $3.8 \%$ & $4.0 \%$ & $6.2 \%$ & $4.8 \%$ & \\
\hline & & Fast food co & sumption & & & \\
\hline $\mathrm{No}$ & 2 & 15 & 5 & 3 & 25 & 0.781 \\
\hline NO & $20.0 \%$ & $28.3 \%$ & $20.0 \%$ & $18.8 \%$ & $24.0 \%$ & \\
\hline Yes & 8 & 38 & 20 & 13 & 79 & \\
\hline Yes & $80.0 \%$ & $71.7 \%$ & $80.0 \%$ & $81.2 \%$ & $76.0 \%$ & \\
\hline & & Main mea & content & & & \\
\hline & 4 & 31 & 12 & 7 & 54 & 0.444 \\
\hline Carbohydrate & $40.0 \%$ & $58.5 \%$ & $48.0 \%$ & $43.8 \%$ & $51.9 \%$ & \\
\hline & 3 & 15 & 6 & 3 & 27 & \\
\hline Protein & $30.0 \%$ & $28.3 \%$ & $24.0 \%$ & $18.8 \%$ & $26.0 \%$ & \\
\hline & 3 & 7 & 7 & 6 & 23 & \\
\hline Fat & $30.0 \%$ & $13.2 \%$ & $28.0 \%$ & $37.5 \%$ & $22.1 \%$ & \\
\hline & & Performing mu & cular exercise & & & \\
\hline $\mathrm{No}$ & 8 & 26 & 11 & 11 & 56 & 0.130 \\
\hline No & $80.0 \%$ & $49.1 \%$ & $44.0 \%$ & $68.8 \%$ & $53.8 \%$ & \\
\hline Yes & 2 & 27 & 14 & 5 & 48 & \\
\hline Yes & $20.0 \%$ & $50.9 \%$ & $56.0 \%$ & $31.2 \%$ & $46.2 \%$ & \\
\hline & & Stress & evel & & & \\
\hline Medium & 5 & 30 & 10 & 1 & 46 & 0.000 \\
\hline Medium & $50.0 \%$ & $56.6 \%$ & $40.0 \%$ & $6.2 \%$ & $44.2 \%$ & \\
\hline & 3 & 12 & 10 & 1 & 26 & \\
\hline Low & $30.0 \%$ & $22.6 \%$ & $40.0 \%$ & $6.2 \%$ & $25.0 \%$ & \\
\hline High & 2 & 10 & 4 & 8 & 24 & \\
\hline High & $20.0 \%$ & $18.9 \%$ & $16.0 \%$ & $50.0 \%$ & $23.1 \%$ & \\
\hline & 0 & 1 & 1 & 6 & 8 & \\
\hline very high & $.0 \%$ & $1.9 \%$ & $4.0 \%$ & $37.5 \%$ & $7.7 \%$ & \\
\hline & & Cause o & stress & & & \\
\hline Fyams & 5 & 25 & 12 & 7 & 49 & 0.951 \\
\hline Exams & $50.0 \%$ & $47.2 \%$ & $48.0 \%$ & $43.8 \%$ & $47.1 \%$ & \\
\hline Social life & 2 & 13 & 4 & 3 & 22 & \\
\hline social ine & $20.0 \%$ & $24.5 \%$ & $16.0 \%$ & $18.8 \%$ & $21.2 \%$ & \\
\hline Family & 2 & 8 & 6 & 2 & 18 & \\
\hline Family & $20.0 \%$ & $15.1 \%$ & $24.0 \%$ & $12.5 \%$ & $17.3 \%$ & \\
\hline Fdurational requirement & 1 & 7 & 3 & 4 & 15 & \\
\hline Eaucauonal requirement & $10.0 \%$ & $13.2 \%$ & $12.0 \%$ & $25.0 \%$ & $14.4 \%$ & \\
\hline & & Dealing w & h stress & & & \\
\hline & 4 & 15 & 10 & 7 & 36 & 0.017 \\
\hline Sleep & $40.0 \%$ & $28.3 \%$ & $40.0 \%$ & $43.8 \%$ & $34.6 \%$ & \\
\hline drink coffee & 2 & 18 & 4 & 1 & 25 & \\
\hline drink coffee & $20.0 \%$ & $34.0 \%$ & $16.0 \%$ & $6.2 \%$ & $24.0 \%$ & \\
\hline Fat & 0 & 7 & 7 & 5 & 19 & \\
\hline Eat & $.0 \%$ & $13.2 \%$ & $28.0 \%$ & $31.2 \%$ & $18.3 \%$ & \\
\hline Other & 1 & 10 & 4 & 3 & 18 & \\
\hline Uther & $10.0 \%$ & $18.9 \%$ & $16.0 \%$ & $18.8 \%$ & $17.3 \%$ & \\
\hline Smoke & 3 & 3 & 0 & 0 & 6 & \\
\hline Smoke & $30.0 \%$ & $5.7 \%$ & $.0 \%$ & $.0 \%$ & $5.8 \%$ & \\
\hline & & Relation betweer & BW and stress & & & \\
\hline & 4 & 21 & 2 & 1 & 28 & 0.004 \\
\hline No & $40.0 \%$ & $39.6 \%$ & $8.0 \%$ & $6.2 \%$ & $26.9 \%$ & \\
\hline & 6 & 32 & 23 & 15 & 76 & \\
\hline Yes & $60.0 \%$ & $60.4 \%$ & $92.0 \%$ & $93.8 \%$ & $73.1 \%$ & \\
\hline
\end{tabular}




\section{Discussion:}

Obesity is emerging as a serious problem throughout the world, not only among adults, but also children, teenagers and young adults ${ }^{[1]}$. It is associated with a large number of debilitating and life-threatening disorders such as cardiovascular, metabolic and other noncommunicable disease ${ }^{[19]}$. Of the factors contributing to obesity, stress seems to be particularly important as stressful condition leads to irregularity in diet, lack of exercise and addiction, each being considered independent factors leading to obesity ${ }^{[20]}$. A nationally representative study found that psychosocial stress increased the risk of future weight gain among adults ages 25 to 74 years with higher baseline body mass index (BMI) but not for adults with lower baseline BMI ${ }^{[21]}$. This is a community-based cross-sectional study carried out among 104 of females student. The aim of the study was to describe the relationship between stress, weight-related health behaviors (e.g., eating behaviors, physical activity, sedentary behavior, sleep, cigarette smoking and binge drinking), and weight status using cross-sectional data from community college students.

Our study found that, as regards stress level; $44.2 \%$ describes stress as medium, $25 \%$ low, $23.1 \%$ high and only $7.7 \%$ very high. $73.1 \%$ of respondents found relation between $\mathrm{BW}$ and stress $(\mathrm{p}=0.004)$. In India another study conducted among total 138 medical students of Jorhat Medical College and Hospital, Jorhat found that overall prevalence of stress $75.3 \%$, the prevalence of high and very highly stressed students are $50(36.2 \%)$ and $54(39.1 \%)$ respectively, and they found a strong correlation between psychological stress and body weight, greater the psychosocial stress more is the body weight $(p=0.007){ }^{[17]}$. Another study was carried out among 973 students from 13 college campuses across the U.S. who had participated in the 15-month YEAH study; $28.1 \%$ reported low stress level, $26.3 \%$ moderate, $21.9 \%$ high and $23.8 \%$ very high, the study found that there were no significant differences found between stress and categorical body mass index scores $(\mathrm{p}=$ 0.539), nor between BMI and eating out frequency $(\mathrm{p}=0.672)^{[22]}$. Another study was done among 1116 participants reported that $29.3 \%$ had low stress level, $38.4 \%$ intermediate and $32.1 \%$ high, Stress was positively correlated with BMI in females, but not in males ${ }^{[15]}$.

As regards body weight, our study showed that, about half students had normal BMI, 24\% were overweight, $15.4 \%$ obese and $9.6 \%$ underweight. Another study reported ; 3.6\% students were obese and only $15.9 \%$ students were overweight ${ }^{[17]}$. Additional study carried out among total of 114 medical students reported; an overall prevalence of overweight was calculated to be $17.5 \%$, prevalence of obesity was $3.4 \%{ }^{[1]}$. Furthermore, it was demonstrated reported that $(69.5 \%$,) of participants fell within the normal BMI while $21.9 \%$ were overweight, and $8.5 \%$ were obese $^{[22]}$. Also,a study reported that $69.6 \%$ of participants were with normal BMI, $22.1 \%$ over weight and only $8.2 \%$ obese ${ }^{[15]}$. In Egypt at Ain Shams University, study involved 317 students; revealed that $41.3 \%$ of the students were of normal weight while $9.5 \%$ of the sample were underweight, $36.9 \%$ were overweight and $12.5 \%$ were obese, obese individuals ate more during feeling of stress compared to non-obese and the difference was statistically significant ${ }^{[23]}$. Another study undertaken among 100 subjects showed that among the subjects, the normal weight (52\%) has the highest prevalence followed by the overweight $(28 \%)$ with the underweight $(7 \%)$ being the lowest ${ }^{[24]}$.

According to causes of stress our study reported that $47.1 \%$ of students considered exams as the main cause of stress, $21.2 \%$ social life, $17.3 \%$ family and $14.4 \%$ for educational requirements. Another study among medical students found that academic problems were a major cause of stress among all students ${ }^{[25]}$.

Our study reported that only $2 \%$ of students regard protein as main meal content, $51.9 \%$ carbohydrate and $22.1 \%$ fat. Another study showed that about $76 \%$ of the participants were on diet that has carbohydrate as the main component while only $24 \%$ were on diet that has protein as the major component ${ }^{[24]}$.

Regarding making exercise this study, revealed that only $46.2 \%$ perform muscular exercise. This was close to another study which reported $46 \%$ of the students engaged in any form of exercise while $54 \%$ of the total students do not engage in any form of exercise ${ }^{[24]}$. Previous study done by stiegler et al. ${ }^{[26]}$ showed that lack of exercise can cause an increase in body weight and the research work 
also done by Cris et al. ${ }^{[27]}$ confirmed that higher amount of activity is necessary for the maintenance of body weight.

\section{Conclusion:}

Several important conclusions can be drawn from the results of this study. Factors which were significantly associated with BMI and stress should be further studied to include number of meals per day, stress level and dealing with stress). Interventions among university students should relate actual measured BMI to stress perception of the students in order to target students at risk. Furthermore, interventions should, depend on the relationship between stress perception and BMI amongst students, focus on exercise, healthy lifestyle, healthy food choices, altering BMI, important stressors and quality of life.

\section{Recommendations:}

Universities should offer individual counselling for at risk students in order to prevent eating disorders, and should offer psychological and stress related counselling, but should also counteract unrealistic body image concerns of students by broad health communication campaigns. Moreover, the association between quality of life and BMI highlights the importance of supporting students throughout their studies, and provide healthy environments, both within the context of university and in their general life.

\section{References:}

1. Gupta S, Ray TG, Saha I (2009): Overweight, obesity and influence of stress on body weight among undergraduate medical students. Indian J Community Med., 34:255257.

2. Lloyd-Richardson E, Bailey S, Fava JL et al. (2009): A prospective study of weight gain duringthe college freshman and sophomore years. Prev Med., 48(3):256-261.

3. Awasthi S, Das R,Verma T et al. (2003): Anemia and under nutrition among preschool children inUttarPradesh,India. Indian Pediatr., 40: 985-990.

4. Snelling AM, Crespo CJ,Schaeffer M et al. (2001): Modifiable and non modifiable factors associated with osteoporosis in postmenopausal women: results from the Third National Health and Nutrition Examination Survey, 1988-1994. JWomens Health Gend Based Med., 10: 57-65.

5. Köpp W, BlumWF, vonPrittwitz $\mathbf{S}$ et al. (1997): Low leptin levels predict amenorrhea in underweight andeatingdisordered females. Mol Psychiatry, 2: 335-340.

6. Brown CD, Higgins M, Donato $\mathrm{K}$ et al. (2000): Body mass index and the prevalence of hypertension anddyslipidemia. Obes Res., 8: 601619.

7. Abdulghani HM (2008): Stress and depression among medical students: A crosssectional study at a medical college in Saudi Arabia. Pak J Med Sci., 24:12-7.

8. Dahlin M, Joneborg N, Runeson B (2005): Stress and depression among medicalstudents: A cross-sectional study. Med Educ., 39:594-604.

9. Sherina MS, Rampal L, Kaneson N (2004): Psychological stress amongundergraduate medical students. Med J Malaysia, 59:207-11.

10. Puder J, Munsch S (2010): Psychological correlates of childhood obesity. International Journal of Obesity, 34, S37-S43.

11. Wardle J, Steptoe A, Oliver G et al. (2000): Stress, dietary restraint and food intake, J Psychosom Res., 482: 195-202.

12. Kivimäki M, Head J, Ferrie J et al. (2006): Work stress, weight gain and weight loss: evidence for bidirectional effects of job strain on body mass index in the Whitehall II study, Int J Obes (Lond), 306:982-987.

13. Kim KH, Bursac Z, DiLillo $V$ et al. (2009): Stress, race, and body weight. Health Psychol., 28(1):131-135.

14. Sinha R, Jastrebof F (2013): Stress as a common risk factor for obesity and addiction AMBiol Psychiatry, 73(9):827-35.

15. McPartl S (2013): Stress, Lifestyle, and Diet in College Students: Analysis of the YEAH Study. https://digitalcommons.uri.edu/cgi/vie wcontent. cgi? article $=1030 \&$ context $=\mathrm{t}$ heses 
16. Dahlin M, Joneborg N, Runeson B (2005): Stress and depression among medicalstudents: A cross-sectional study. Med Educ.,39:594-604.

17. Goswami B (2017: Prevalence of Stress and its Association with Body Weight Among the Medical Students of Jorhat Medical College and Hospital, Jorhat. Int J Sci Stud., 4(11):1-3.

18. Pelletier JE, Leslie AL, Melissa N L (2017): Stress, Health Risk Behaviors, and Weight Status among Community College Students. Health education \& behavior: the official publication of the Society for Public Health Education, 43(2): 139-144.

19. Deotale M, Ranganathan U, Akarte $S$ (2015): Prevalence of overweight and obesity among medical students and their knowledge, attitude and practices about obesity.IntJ Sci Rep.,1(1):74-9.

20. Kumar S, Mahabalaraju KD, Anuroopa MS (2007): Prevalence of obesity and its influencing factor among affluent school children of Devanagere City. Indian Journal of Community Medicine, 32:15-7.

21. Block JP, He Y, Zaslavsky A et al. (2009): Psychosocial stress and change in weight among US adults. American Journal of Epidemiology, 170: 181-192.
22. Nicholas SE (2016): The Effect of Stress on Undergraduate College Students in Relation to Eating Out Behaviors and WeightStatus. https://surface.syr.edu/etd/480

23. Bakr EM, Ismail NA, Mahaba HM (2002): Impact of life style on the nutritional status of medical students at Ain Shams University. J Egypt Public Health Assoc., 77(1-2):29-49.

24. Katuka SK, Faleti OC, Medavarapu S et al. (2016): The Prevalence of Underweight, Overweight, Obesity and the influnce of Exercise and Diet on Body Weight among Medical Students. Arch Med., 8:5.

25. Saipanish R (2003): Stress among medical students in a Thai medical school. Med Teach., 25:502-6.

26. Stiegler P, cunliffe A (2006): The role of diet and exercise for the maintenance of fat-free mass and resting metabolic rate during weight loss. Sports Med., 36: 239-262.

27. Slentz C, Duscha B, Johnson J et al.(2004) effect of the amount of exercise on body weight, body compositionn and measures of central obesity. Arch Intern Med., 164: 31-39. 